\title{
Characterization of Anthocyanins from Fruits of Two Mexican Chili Peppers (Capsicum annuum L.)
}

\author{
César Aza-González ${ }^{1}$ and N. Ochoa-Alejo ${ }^{1,2 *}$
}

${ }^{1}$ Departamento de Ingeniería Genética de Plantas, Centro de Investigación y de Estudios Avanzados del Instituto Politécnico Nacional (Cinvestav-Unidad Irapuato). Km. 9.6 Libramiento Norte Carretera Irapuato-León; Apartado Postal 629; 36821 Irapuato, Gto., México.nochoa@ira.cinvestav.mx

2 Departamento de Biotecnología y Bioquímica, Centro de Investigación y de Estudios Avanzados del Instituto Politécnico Nacional (Cinvestav-Unidad Irapuato). Km. 9.6 Libramiento Norte Carretera Irapuato-León; Apartado Postal 629; 36821 Irapuato, Gto., México.

Received October 3, 2011; accepted March 9, 2012

\begin{abstract}
Chili pepper fruits of the Árbol and Uvilla types (Capsicum annuит L.) were analyzed to characterize the anthocyanins that are synthesized and accumulated in the pericarp tissues. The aglycon delphinidin was identified as the only anthocyanidin in both chili peppers. Anthocyanins were separated and identified using HPLC-MS, and delphinidin-3-cis-coumaroylrutinoside-5-glucoside and delphinidin-3-trans-coumaroylrutinoside-5-glucoside were the most abundant components.

Key words: Anthocyanins, Capsicum, chili pepper, fruits, pericarp.
\end{abstract}

\section{Introduction}

Chili pepper (Capsicum spp.) is one of the most important food additives worldwide. Its significance derives mainly from the great diversity in fruit shape, size, pungency, color, aroma and flavor. Approximately 27-30 Capsicum species have been described, but only five (Capsicum annum L., C. baccatum L., C. chinense Jacq., C. frutescens $\mathrm{L}$. and C. pubescens Ruiz \& Pavon) have been domesticated and cultivated [1]. In Mexico, chili peppers play fundamental roles in both culture and cuisine as a result of their broad utilization in most typical dishes. The most significant compounds synthesized and accumulated in chili pepper fruits are capsaicinoids (responsible for the pungent taste), vitamins (A, C and E) and pigments (anthocyanins and carotenoids) $[2,3]$. Due to the presence of each of these compounds, chili peppers are commonly used in food, pharmaceutical and cosmetic industries.

Anthocyanins are pigments widespread in nature that are responsible for fruit, stem, leaf, flower, tuber and root colors (orange, red, purple and blue) in many plant species [4-6]. These compounds have several biological functions, including attracting pollinators and preventing photo-oxidative plant damage. The protection conferred against UV damage is related to their antioxidant capacity, which has been extensively studied in many plants. Anthocyanins have also been shown to display important nutraceutical properties that prevent heart disease and cancer, which may also be linked to their antioxidant capacity [7-12].

Studies on anthocyanins in chili pepper are very scarce. Hitherto, few papers have described the presence of anthocya-
Resumen. Frutos de chile de Árbol y Uvilla (Capsicum annuum L.) fueron analizados para caracterizar las antocianinas que se sintetizan y se acumulan en el pericarpio. La aglicona delfinidina fue identificada como la única antocianidina presente en ambos tipos de frutos. Las antocianinas fueron separadas e identificadas por HPLC-MS, y se determinó que la delfinidina-3-cis-cumaroilrutinosido-5-glucósido y la delfinidina-3-trans-cumaroilrutinosido-5-glucósido fueron los componentes más abundantes.

Palabras clave: Antocianinas, Capsicum, chile, frutos, pericarpio.

nins in chili pepper fruits. For instance, delphinidin was reported as the possible anthocyanidin present in fruits of an Israelicultivar (C. апnиum) [13]. Likewise, an analysis of a German chili pepper (C. аппиит) revealed that the main anthocyanins were delphinidin-3-trans-coumaroylrutinoside-5-glucoside (nasunin) and delphinidin-3-cis coumaroylrutinoside-5-glucoside, among others [14]. More recently, delphinidin-3-p-coumaroylrutinoside-5-glucoside was reported as the single anthocyanin present in violet and black chili pepper fruits [15]. Additional research aimed at identifying and characterizing anthocyanins from more chili pepper fruit varieties and species is needed to supplement the aforementioned studies. In this study, the identity of anthocyanins in two Mexican chili pepper types was investigated.

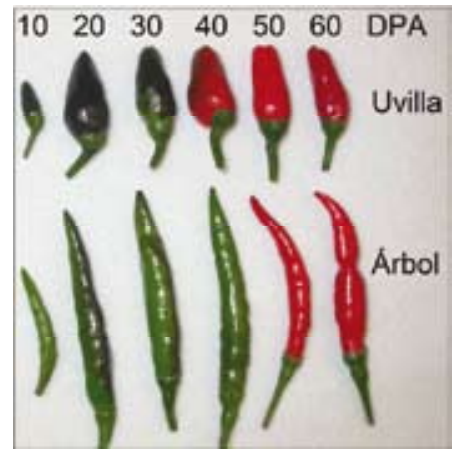

Fig. 1. Developmental stages of Uvilla and Árbol chili pepper fruits. DPA: Days post-anthesis. 


\section{Results and Discussion}

In order to characterize chili pepper anthocyanidins, fruit-methanolic extracts were prepared from pericarp tissues of fruits Árbol and Uvilla types (C. annuиm L.) (Fig. 1). Extracts were injected and separated by HPLC, and anthocyanidins were identified by comparison with several commercial standards (Fig. 2a). Delphinidin was the only anthocyanidin found in both chili pepper types (Fig. 2b). Previously, Borovsky et al. (2004)[13] reported only preliminary evidence suggesting that delphinidin might be the anthocyanidin accumulated in purple chili pepper fruits of the inbred line 5226 (C. annuum L.).

HPLC-diode array detector (DAD) and mass spectrometry (MS) were used to identify the anthocyanins in the two Mexican chili pepper types (Fig. 3). The main components were found at 40.54 min (peak 1) and 45.25 min (peak 2) (Fig. 3a). In order to distinguish the compounds and structures linked to the aglycon delphinidin, the two most abundant components separated by HPLC (peaks 1 and 2) were purified and analyzed by MS (Fig. $3 a$ ). Both samples yielded the same molecular mass (919) and the same fragmentation profile (757, 465 and 303) (Fig. 3b), which corresponded to nasunin [16]. The fragmentation peaks corresponded to $\mathrm{m} / \mathrm{z} 757$ for one hexose loss, to $\mathrm{m} / \mathrm{z} 465$ for $p$-coumaroyl-hexose loss and to $\mathrm{m} / \mathrm{z} 303$ for the aglycon delphinidin [16]. Using the maximum wave-length absorption for each component, $530 \mathrm{~nm}$ for trans isomer and $532 \mathrm{~nm}$ for cis isomer [14], the compounds were identified as delphinidin-3cis-coumaroylrutinoside-5-glucoside (peak 1) and delphinidin3-trans-coumaroylrutinoside-5-glucoside (peak 2). The relative

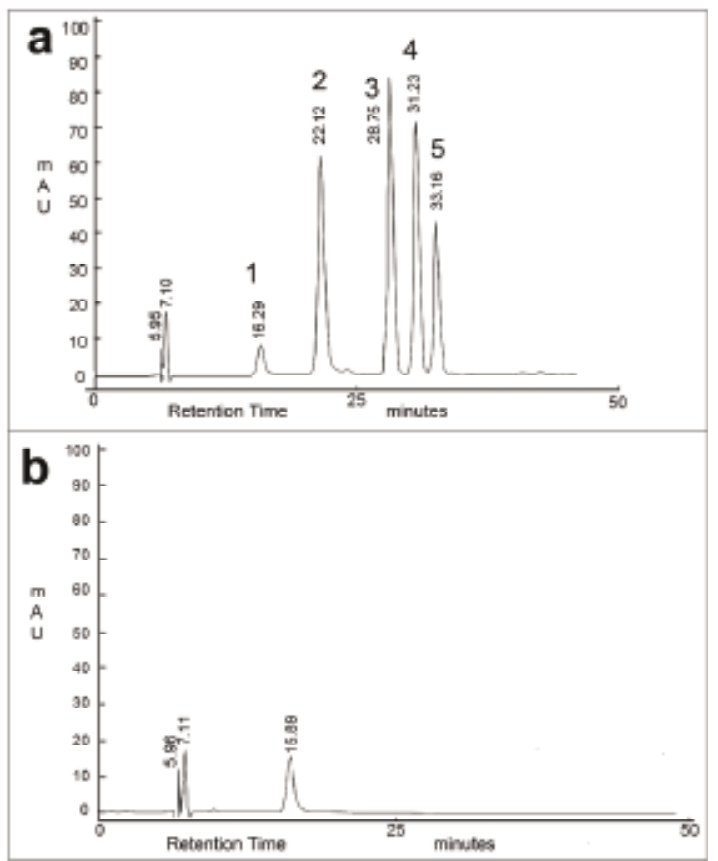

Fig. 2. Anthocyanidin HPLC profiles of chili pepper fruits. $\boldsymbol{a} \mathbf{- 1}$ : delphinidin, 2: cyanidin, 3: pelargonidin, 4: peonidin and 5: malvidin aglycon standards; $\boldsymbol{b}$ - a combined hydrolyzed extract from Árbol and Uvilla chili pepper fruits at 20 days post-anthesis. The two peaks at 5.9 and $7.1 \mathrm{~min}$ in the extract correspond to solvent front of the sample.

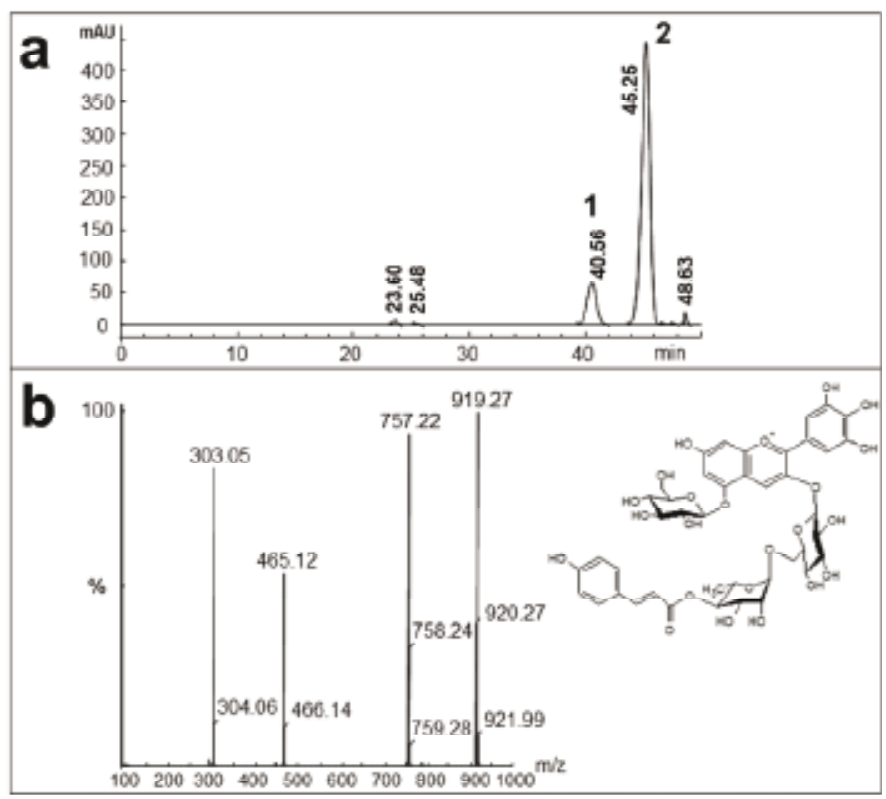

Fig. 3. Anthocyanin characterization. $\boldsymbol{a}$ - HPLC chromatograms of chili pepper Uvilla pericarp tissues at 20 DPA; $\boldsymbol{b}$ - Fragmentation profile of peak 2 compound (in HPLC), which was identified as delphinidin3-trans-coumaroylrutinoside-5-glucoside.

contributions of these two components was $13.8 \%$ for the cis and $84.4 \%$ for the trans isomer, which agrees with results reported by Sadilova et al. (2006)[14], who found $4.6 \%$ of the cis and $89 \%$ of the trans isomer in violet chili pepper fruits. They also recorded the presence of delphinidin-3-caffeoylrutinoside-5-glucoside (2.4\%), delphinidin-3-feruloylrutinoside5 -hexoside $(1.2 \%)$, delphinidin-3-rutinoside $(0.9 \%)$, delphinidin-3-glucoside $(0.7 \%)$, delphinidin-3-rhamnoside $(0.7 \%)$ and delphinidin-3-rutinoside-5-glucoside (0.5\%). Lightbourn et al. (2008)[15] analyzed anthocyanins extracted from C. annuum genotypes G05C69-12 (black fruit/black foliage) and G05C7412 (violet fruit/green foliage) and found delphinidin-3-coumaroyl-rutinoside-5-glucoside to be the only anthocyanin. Our results provide additional evidence in favor of nasunin as the principal anthocyanin accumulated in partially or completely black anthocyanin-pigmented C. annuum fruits [14].

In conclusion, Árbol and Uvilla chili pepper fruits accumulated only delphinidin derivatives. Delphinidin-3-cis-coumaroylrutinoside-5-glucoside and delphinidin-3-trans-coumaroylrutinoside-5-glucoside were the most important anthocyanins, together representing $\mathrm{ca}$. $98 \%$ of the total anthocyanin content. This is the first report on anthocyanin characterization produced by Mexican chili pepper fruits.

\section{Experimental section}

\section{Plant material}

Seeds of chili pepper Árbol (partially anthocyanin-pigmented fruits) and Uvilla types (totally black anthocyanin-pigmented 
fruits) (Capsicum annuum L.) were germinated in 100-mL plastic pots, and the seedlings were transplanted to $10-\mathrm{L}$ plastic pots after three weeks of germination. A soil mixture constituted by three parts of Sunshine Mix 3 (SunGro Horticulture, USA), one part of Vermiculite (SunGro Horticulture, USA), one part of Perlite (Perlita de La Laguna, S.A. de C.V., Durango, Mexico), one part of sludge and two parts of forest soil was used for germination and development of plants. Plants were grown under greenhouse conditions and fertilized every two weeks with a FerVialFol (Agroquímicos Rivas, Gto., Mexico) solution (N:P: K-30:20:10) containing macro and micronutrients.

Fruits were harvested, the pericarp tissue was directly dissected from the fruits, and immediately immersed into liquid nitrogen and kept at $-80{ }^{\circ} \mathrm{C}$. Pericarp tissue was used for anthocyanin extraction.

\section{Analysis of anthocyanidins and anthocyanins}

All anthocyanin protocols were carried out while protecting the samples from direct light. Anthocyanins from only pigmented pericarp tissue $\left(1 \mathrm{~g}\right.$ fresh weight; samples stored at $\left.-80{ }^{\circ} \mathrm{C}\right)$ from both Árbol and Uvilla pepper types were extracted with $10 \mathrm{~mL}$ of cooled-acidified methanol (methanol:distilled water: acetic acid 11:5:1 v/v) at room temperature for $30 \mathrm{~min}$ under agitation and protected from light, following a previously reported method [13]. Briefly, anthocyanin-methanolic extracts were centrifuged at 12,000 rpm for $10 \mathrm{~min}$ at room temperature and the supernatant was concentrated to $0.5 \mathrm{~mL}$ under reduced pressure in a rotary evaporator $\left(41^{\circ} \mathrm{C}\right)$. To release the anthocyanidins (aglycons), the anthocyanin extracts were adjusted to $2 \mathrm{~N} \mathrm{HCl}$, hydrolyzed at boiling temperature for $1 \mathrm{~h}$, and then centrifuged at $12,000 \mathrm{rpm}$ for $10 \mathrm{~min}$ at room temperature. The supernatant was recovered, treated with an equal volume of ethyl acetate, and centrifuged as described above. The ethyl acetate phase was eliminated, and the treatment step was repeated once more with the aqueous phase. Samples were further heated at $80{ }^{\circ} \mathrm{C}$ for $3 \mathrm{~min}$ to eliminate ethyl acetate residue, and the anthocyanidins were extracted with an equal volume of isoamyl alcohol. After centrifugation, the isoamyl alcohol phase was recovered and dried at $35^{\circ} \mathrm{C}$. Finally, the residue was dissolved in $1 \mathrm{~mL}$ of methanol: $\mathrm{HCl}(100: 0.01 \mathrm{v} / \mathrm{v})$. Anthocyanidin separation was carried out in a LC-1445 HPLC (GBC, Australia) apparatus equipped with a pump LC1150, a UV-VIS detector LC1205K and a C18 column (Vydac 201SP54, CA). Conditions for separation were according with those previously reported [13]. Detection of anthocyanidins and anthocyanins was carried out at $530 \mathrm{~nm}$. For anthocyanidin identification, the retention times of commercial standards were used (cyanidin, delphinidin, malvidin, pelargonidin and peonidin; ChromaDex, Laguna Hills, CA).

Anthocyanins were separated using a 1200 HPLC (Agilent Technologies, Waldbronn, Germany) apparatus equipped with an autosampler G1364C, a pump G1312A, a diode array detector G1315B and an analytical C18 column (Vydac 201SP54, $\mathrm{CA})$, at constant temperature $\left(25^{\circ} \mathrm{C}\right)$ and at $1 \mathrm{~mL} \mathrm{~min}^{-1}$ flow rate, according with a previously reported procedure [14]. For anthocyanin characterization, a Micromass Q-Tof Micro Hybrid Quadrupole/Orthogonal Mass Spectrometer system (Waters Corporation, Milford, MA) equipped with a nanospray ionization source was employed. ESI capillary voltage was fixed at $900 \mathrm{~V}$ and the cone voltage was set at $35 \mathrm{~V}$. The mass spectrometer was calibrated using a mix of sodium iodide and cesium within a range of 50-2000 Da. Argon was used for collision and the energy employed was between 23 and $45 \mathrm{eV}$. MassLynx version 4.0 software (Micromass, UK) was used for data analysis.

\section{Acknowledgements}

We acknowledge the National Council for Science and Technology (Conacyt; Mexico) for the fellowship to César AzaGonzález. The authors would like to thank Alicia Chagolla for her technical assistance with the anthocyanin-MS analysis. This work was partially supported by grants from Fondos Mixtos Guanajuato (projects GTO-04-C02-24 and GTO-2005-C02-50), Conacyt (Project 55264) and SAGARPA (project 11806).

\section{References}

1. Csilléry, G. Acta Agron. Hung. 2006, 54, 151-166.

2. Osuna-García, J. A.; Wall, M. M.; Waddell, C. A. J. Agric. Food Chem. 1998, 46, 5093-5096.

3. Marin, A.; Ferreres, F.; Tomás-Barberán, F. A.; Gil, M. I. J. Agric. Food Chem. 2004, 52, 3861-3869.

4. Holton, T. A.; Cornish, E. Plant Cell 1995, 7, 1071-1083.

5. Wu, X.; Prior, R. L. J. Agric. Food Chem. 1998, 53, 3101-3113.

6. Grotewold, E. Annu. Rev. Plant Biol. 2006, 57, 761-780.

7. Wang, H.; Nair, M. G.; Strasburg, G. M.; Chang, Y. C.; Booren, A. M.; Gray, J. I.; DeWitt, D. L. J. Nat. Prod. 1999, 62, 294-296.

8. Chen, P. N.; Chu, S. C.; Chiou, H. L.; Chiang, C. L.; Yang, S. F.; Hsieh, Y. S. Nutr. Cancer 2005, 53, 232-243.

9. Reddy, M. K.; Alexander-Lindo, R. L.; Nair, M. G. J. Agric. Food Chem. 2005, 53, 9268-9273.

10. Bell, D. R.; Gochenaur, K. J. Appl. Physiol. 2006, 100, 11641170.

11. Chen, P. N.; Chu, S. C.; Chiou, H. L.; Kuo, W. H.; Chiang, C. L.; Hsieh, Y. S. Cancer Lett. 2006, 235, 248-259.

12. Lamy, S.; Lafleur, R.; Bédard, V.; Moghrabi, A.; Barrette, S.; Gingras, D.; Béliveau, R. J. Cell. Biochem. 2007, 100, 100-111.

13. Borovsky, Y.; Oren-Shamir, M.; Ovadia, R.; De Jong, W.; Paran, I. Theor. Appl. Genet. 2004, 109, 23-29.

14. Sadilova, E.; Stintzing, F. C.; Carle, R. Z. Naturforsch. [C] 2006, 61, 527-535.

15. Lightbourn, G. J.; Griesbach, R. J.; Novotny, J. A.; Clevidence, B. A.; Rao, D. D.; Stommel, J. R. J. Hered. 2008, 99, 105-111.

16. Ichiyanagi, T.; Kashiwada, Y.; Shida, Y.; Ikeshiro, Y.; Kaneyuki, T.; Konishi, T. J. Agric. Food Chem. 2005, 53, 9472-9477. 